\title{
Long-term results of refractory glaucoma cases with Ahmed glaucoma valve implantation
}

\section{Dirençli glokom vakalarında Ahmet glokom valf implantasyonunun uzun dönem klinik sonuçları}

Serpil YAZGAN ${ }^{1}$, Uğur ÇELiK ${ }^{2}$, Sılay CANTÜRK UĞURBAŞ ${ }^{1}$, Şükrü BAYRAKTAR ${ }^{3}$, Ömer Faruk YILMAZ ${ }^{3}$

\section{ABSTRACT}

To evaluate long- term effects of Ahmed glaucoma valve (AGV) implantation in refractory glaucoma cases on intraocular pressure, visual acuity and cornea. The cases who had undergone AGV implantation between the years 2003 to 2014 with the diagnosis of refractory glaucoma were evaluated retrospectively. The cases with minimal light perception visual acuity and followed up for longer than 12 months were selected. Preoperative and postoperative corrected distance visual acuity levels (CDVA), intraocular pressure (IOP), number of medications and central corneal thickness (CCT) were recorded. Complications and additional surgeries were noted. The complete surgical cure was based on following considerations: no need for additional surgery, achievement of mean IOP level between 5-22 $\mathrm{mmHg}$, stability of visual acuity and corneal transparency. Forty eight eyes of 47 refractory glaucoma cases with neovascular $(n=13)$, aphasic $(n=13)$, secondary to penetrating keratoplasty $(P K)(n=7)$, congenital $(n=4)$, traumatic $(n=5)$ and primary refractory glaucoma $(n=6)$ were evaluated. Mean age $(50.40 \pm 22.80$ years), mean follow-up period ( $32.33 \pm 20.78$ (12-84) months), preoperative

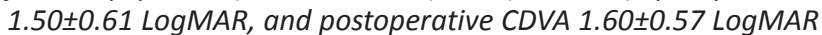
were determined. IOP values ( $39.22 \pm 9.47$ vs $17.02 \pm 4.29 \mathrm{~mm} \mathrm{Hg}$ ), number of medications (3.47 \pm 0.92 vs $1.52 \pm 1.09)$, CCT values (590.00 \pm 88.86 vs $655.25 \pm 170.88 \mu \mathrm{m}$ ( $p<0.05$ were also estimated. Additional surgeries were performed including drainage of suprachoroidal hemorrhage $(n=1)$, cleaning of AGV tip $(n=5)$, anterior vitrectomy $(n=5), A G V$ reposition $(n=3), A G V$ tip shortening $(n=6)$, corneal graft insufficiency related $P K(n=3)$, and additional cyclodestructive procedures $(n=5)$. Perfect surgical, total surgical success rates were detected as $46 \%(n=22)$, and $89.4 \%$ $(n=43)$, respectively. However surgery failed in 5 (10.6\%) cases AGV was a considerable successful surgical option for decreasing the IOP in refractory glaucoma cases. However even there is not a significant AGV endothelial touch, endothelial insufficiency related corneal edema and eventual visual loss was seen.

Key words: Ahmed glaucoma valve, refractory glaucoma, corneal edema
Öz

Dirençli glokom vakalarında Ahmed glokom valf (AGV) implantasyonunun göz içi basıncı, görme keskinliği ve kornea üzerindeki uzun dönem etkilerini değerlendirmektir. 2003-2014 yılları arasında dirençli glokom tanısıyla Ahmed valf implantasyonu yapılan vakalar geriye dönük incelendi. Görme keskinliği en az ışık hissi düzeyinde olan ve 12 ay takip süresi olan hastalar seçildi. Ameliyat öncesi ve son muayenedeki en iyi düzeltilmiş görme keskinliği (EIDGK), göz içi basıncı (GiB), medikasyon sayısı ve merkezi kornea kalınlığı (MKK) kaydedildi. Komplikasyonlar ve uygulanan ilave cerrahiler not edildi. llave glokom cerrahilerine gereksinim duyulmadan GiB'nın ilaçlı/ilaçsız 5-22 mmHg olması ve görme keskinliğinin korunması ve kornea saydamlığının devamlılığı tam cerrahi başarı sayıldı. Neovasküler ( $n=13)$, afakik $(n=13)$, penetran keratoplastiye ikincil $(n=7)$, konjenital $(n=4)$, travmatik $(n=5)$ ve primer dirençli glokom ( $n=6)$ olmak üzere 47 dirençli glokom vakasının 48 gözü değerlendirildi. Yaş ortalaması 50,40 $\pm 22,80$ yıl, takip süresi 32,33 $\pm 20,78(12-84)$ ay, operasyon öncesi ve son ta-

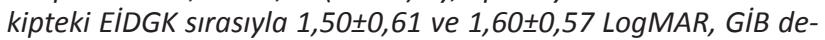
ğerleri sırasıyla 39,22 $\pm 9,47$ ve $17,02 \pm 4,29 \mathrm{mmHg}$, medikasyon sa-

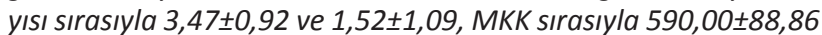
ve $655,25 \pm 170,88$ mikron saptand $(p<0,05)$. Ilave uygulanan cerrahiler; suprakoroidal hemoraji drenajı $(n=1)$, tüp ucu temizliği $(n=5)$, anteriyor vitrektomi $(n=5)$, tüp repozisyonu ( $n=3)$, tüp ucu kısaltılması $(n=6)$, grefon/korneal yetmezlik nedeniyle PK $(n=3)$, ilave siklodestriktif işlem $(n=5)$ şeklindeydi. Tam cerrahi, toplam ve başarısızlık oranları sırasıyla \%46 $(n=22), \% 89,4(n=43), \% 10,6$ $(n=5)$ olarak saptand. AGV ile dirençli glokom vakalarında tatmin edici göz içi basıncı düşüşü sağlanmaktadır. Ancak zamanla görünür bir tüp-endotel teması olmasa bile, endotel yetmezliğine bağlı kornea ödemi ve görme kaybı oluşmaktadır.

Anahtar kelimeler: Ahmed glokom valfi, dirençli glokom, kornea ödemi

Received: 08.02.2016

Accepted: 23.02.2016

${ }^{1}$ Bülent Ecevit University, School of Medicine, Department of Ophthalmology

${ }^{2}$ istanbul Medeniyet University, School of Medicine, Department of Ophthalmology

${ }^{3}$ Beyoğlu Eye Research and Training Hospital, Glaucoma Department

Yazışma adresi: Uğur Çelik, İstanbul Medeniyet University, School of Medicine, Department of Ophthalmology, İstanbul e-mail: h.ugurcelik@gmail.com 


\section{Giriş}

Öncesinde klasik filtran cerrahi geçirmiş ve başarısız olunmuş vakalar (afakik/psödofakik glokom, konjenital glokom, penetran keratoplastiye ikincil glokom vakaları gibi) ve klasik filtran cerrahinin başarısız olacağını düşündüren glokom tipleri (neovasküler glokom, bazı travmatik glokom vakaları gibi) dirençli glokom olarak değerlendirilir ${ }^{1}$. Dirençli glokom vakaları için önerilen tedavi yöntemleri genellikle antimetabolit uygulanarak trabekülektomi cerrahisinin yinelenmesi, tüp implantasyon cerrahisi veya siliyer cismi tahrip edici yöntemlerdir ${ }^{1-4}$. Tüp drenaj implantlarında aköz hümör tüp aracılığıyla ön kamaradan orbital dokuya direkt olarak drene olur. İlk üretilen tüp olan Molteno implantı ve Baerveldt implantları valf yapısı içermedikleri için persiste hipotoni bu tip tüplerin en önemli komplikasyonları olarak bildirilmiştir ${ }^{5,6}$. Ancak belli bir basınçta drenaj sistemini devreye sokan bir valf sistemi içeren ve böylece kontrollü GiB düşüşü sağlayan Ahmed glokom valfi ve Krupin implantları hipotoniyi engelleyerek bu cerrahiyi daha güvenilir hâle getirmişlerdir ${ }^{6,7}$. Ahmed glokom valvinin dirençli glokom vakalarında başarıyla kullanıldığını destekleyen birçok çalışma mevcut olmak ile birlikte uzun dönem klinik sonuçlarını bildiren çalışma sayısı kısıtlıdır ${ }^{8-10}$.

Bu çalışmada, amacımız dirençli glokom vakalarında Ahmed valf implantasyonunun göz içi basıncı, görme keskinliği ve kornea üzerindeki uzun dönem etkilerini afakik, psödofakik ve fakik vakalardaki başarılarını değerlendirmektir.

\section{GEREÇ ve YÖNTEM}

\section{Hasta seçimi}

Çalışmamız 2 merkezde yürütülmüştür. Vakalar 20032014 yılları arasında dirençli glokom nedeniyle Ahmed glokom valf implantasyonu yapılan vakalardan geriye dönük incelenerek elde edilmiştir. Çalışma Helsinki Bildirgesi prensiplerine bağlı kalınarak ve çalışmaya dâhil edilen bütün hastalardan bilgilendirilmiş onam alınarak yapıldı. Ayrıca çalışma için Etik Kuruldan uygunluk onayı alındı. Görme keskinliği en az ışık hissi düzeyinde olan ve 12 aydan fazla takip süresi olan hastalar çalışmaya dâhil edildi. Neovasküler glokom (NVG), penetran keratoplastiye (PK) ikincil glokom, daha önce başarısız trabekülektomi geçirmiş afakik veya psödofakik glokom, konjenital glokom, travmatik glokom ve primer refrakter glokom dirençli glokom olarak kabul edildi.

Hastaların yaş, cinsiyet gibi demografik bilgileri, glokomun tipi, daha önce geçirdikleri göz cerrahileri, ameliyat öncesi ve sonrası en iyi düzeltilmiş görme keskinliği, göz içi basıncı (GiB), medikasyon sayısı, merkezi kornea kalınlığı (MKK) değerleri kaydedildi. Ameliyat sırasında ve sonrasında meydana gelen komplikasyonlar; suprakoroidal kanama, vitreus içi kanama, koroid efüzyonu ve koroid dekolmanı, hipotoni ve hipotoni makülopatisi, endoftalmi, retina dekolmanı, valve bağlı ciddi bakış kısıtııı̆̆ ve çift görme, plak migrasyonu, tüpün yer değiştirmesi, konjonktival erozyon, tüp ucunun tıkanması (kan, fibrin veya vitreus nedeniyle), tüp ucunun kornea teması gibi, kornea yetmezliği veya grefon opaklaşması not edildi. Hastalara gerek duyulan tüp/bleb revizyonu, tüp ucunun kısaltılması, tüp veya gövdenin yeniden pozisyonlandırılması, valvin çıkarılması, siklodestrüktif prosedürler, kornea veya grefon opaklaşması nedeniyle keratoplasti uygulamaları gibi ilave cerrahi girişimler not edildi. İlave siklodestrüktif cerrahi uygulanmış vakalarda son muayene bulguları ve takip süresi olarak siklodestrüktif prosedür uygulanana kadar olan dönem kabul edildi.

\section{Cerrahi başarı}

İlave glokom cerrahi prosedürlerine gereksinim duyulmaksızın GiB değerlerinin ilaçlı veya ilaçsız 5-22 $\mathrm{mmHg}$ arasında olması ve görme keskinliğinin korunması ve korneanın saydamlığını sürdürmesi tam cerrahi başarı olarak değerlendirildi. İlave glokom cerrahi prosedürlerine gereksinim duyulmaksızın, GiB değerinin ilaçlı ya da ilaçsız 5-22 mmHg arasında olmasına rağmen, görme keskinliği azalan ve kornea dekompansasyonu gelişen vakalar kısmi başarı olarak değerlendirildi. Işık persepsiyonunun kaybı, persiste hipotoni $(<5 \mathrm{mmHg}$ ) ve hipotoniye bağlı gelişen kalıcı 
görme kaybı, valvin çıkarılması, siklodestrüktif prosedürler gibi ilave glokom cerrahilerinin uygulanması tam başarısızlık olarak değerlendirildi.

\section{Ameliyat prosedürü}

Erişkin vakalarda AGV'nin S2 modeli (yüzey alanı 184 $\mathrm{mm}^{2}, 16 \mathrm{~mm}$ uzunluğunda, $13 \mathrm{~mm}$ genişliğinde, 1.9 $\mathrm{mm}$ kalınlığında polipropilen gövde, $12 \mathrm{mmHg}$ basınca duyarlı), konjenital glokom vakalarında AGV'nin S3 pediatrik modeli (yüzey alanı $96 \mathrm{~mm}^{2}$, gövde uzunluğu $10 \mathrm{~mm}$ ve genişliği $9.6 \mathrm{~mm}$ ) kullanıldı. Operasyonlar üç ayrı cerrah tarafından yapıldı (ŞB, SCU, SY). İmplantasyon için 40 vakada üst temporal kadran, 6 vakada üst nazal kadran, 2 vakada alt temporal kadran seçildi. Konjonktiva, implantasyonun uygulanacağı alanda 90 derece ve forniks tabanlı olarak açıldı. Daha sonra $1 / 2$ kalınlıkta, 4x5 mm ebatında limbus tabanlı skleral flep oluşturuldu. Skleral flebin gerisinden $3 \mathrm{~mm}$ 'lik skleral cep oluşturuldu. Valf mekanizmasının çalışırIılığını kontrol etmek ve aktive etmek için tüp boşluğundan BSS sıvısı verildi. Valvin rezervuarı(plate) konjonktivanın altından globun ekvator bölgesine yerleştirildi ve 10-0 naylon sütür ile limbusa $8-10 \mathrm{~mm}$ mesafeden skleraya sütüre edildi. Skleral flebin altından 22 gauge iğne ucu ile ön kamaraya girildi. Silikon tüp 3 mm'lik skleral cepten geçirildi. Tüpün ucu 2-3 $\mathrm{mm}$ ön kamarada kalacak şekilde eğik olarak kesildi ve ön kamaraya yerleştirildi. Skleral flep 10/0 naylon ile separe sütüre edildi, konjonktiva kontinü olarak $8 / 0$ vikril sütür ile kapatıldı.

\section{İstatistik}

İstatistik analizi SPSS 19.0 yazılım programı ile yapıldı (SPSS Inc., Chicago, IL, USA). Normal dağılıma uygunluk Shapiro-Wilk testi ile değerlendirildi. Sayısal değişkenler ortalama ' \pm ' standart hata veya ortanca (minimummaksimum) olarak sunuldu. Kategorik değişkenler sıklık ve oran olarak sunuldu. Kategorik değişkenlerin karşılaştırılmasında Pearson ki-kare testi kullanıldı. Normal dağıııma uyan sayısal değişkenler Student $t$ testi ile normal dağılıma uymayan parametreler Wilcoxon işaret testi ile karşılaştırıldı. Tüm testler için $\mathrm{p}$ değeri 0,05'ten küçük olduğunda anlamlı kabul edildi.

\section{BULGULAR}

Yaş ortalaması $50,40 \pm 22,80$ olan, $25^{\prime}$ i kadın $(\% 53,2)$ ve 22'si erkek olan 47 vakanın 48 gözü çalışmaya dâhil edildi. Vakaların glokom tipinin dağılımı 13 vaka NVG, 13 vaka afakik glokom, 7 vaka PK'ye ikincil glokom, 6 vaka primer dirençli glokom, 5 vaka travmatik ve 4 vaka konjenital glokom şeklindeydi. Ortalama takip süresi $32,33 \pm 20,78$ ay (12-84 ay) idi (Tablo 1$)$. Penetran keratoplasti uygulanan vakalar; 4 vaka psödofakik büllöz keratopati, 2 vaka travmatik korneal lökom ve 1 vaka kimyasal yanık nedeniyle korneal yetmezlik gelişen ve PK uygulanmış vakalardı.

Tablo 1. AGV implantasyonu yapılan vakaların demografik bilgileri.

\begin{tabular}{|c|c|}
\hline \multicolumn{2}{|l|}{$\mathrm{N}=48$} \\
\hline Yaş (yıl) & $50,40 \pm 22,80$ (3-90 yaş) \\
\hline \multicolumn{2}{|l|}{ Cinsiyet } \\
\hline Kadın, \% & $25(53,2)$ \\
\hline Erkek, \% & $22(46,8)$ \\
\hline \multicolumn{2}{|l|}{ Glokomun Nedeni, (\%) } \\
\hline Neovasküler & $13(27,1)$ \\
\hline Afakik & $13(27,1)$ \\
\hline Penetran keratoplasti sonrası & $7(14,5)$ \\
\hline Primer dirençli & $6(12,5)$ \\
\hline Travmatik & $5(10,4)$ \\
\hline Konjenital & $4(8,3)$ \\
\hline Takip Süresi, Ay (ort. $\pm S D)$ & $32,33 \pm 20,78$ (12-84 ay) \\
\hline
\end{tabular}

Ahmed glokom valf implantasyonu öncesinde vakaların ortalama göz içi basıncı 39,22 $\pm 9,47 \mathrm{mmHg}$ iken son muayenede $17,02 \pm 4,29 \mathrm{mmHg}$ saptandı. $(p<0,001)$ Etken madde sayısına göre kullanılan ortalama topikal anti-glokomatöz sayısı implantasyon

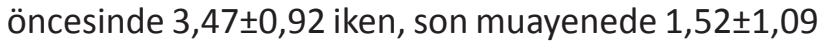
saptandı $(p<0,001)$. En iyi düzeltilmiş görme keskinliği değerleri LogMAR sistemine göre AGV öncesi

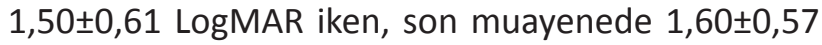
LogMAR saptandı $(p=0,046)$. Implantasyon öncesi ortalama MKK değeri $590,00 \pm 88,86 \mu$ iken, son muayenede $655,25 \pm 170,88 \mu$ saptandı $(p=0,002)$. Ameliyat öncesi farklı düzeylerde kornea veya grefon yetmezliği olan vaka sayısı $8(\% 16,6)$ iken, son muayenede bu sayı 20 (12 yeni vaka ilave oldu, \%41,6) tespit edildi $(p=0,001)$ (Tablo 2$)$. 
Tablo 2. Ahmet valfi takılan vakaların ameliyat öncesi ve son muayene bulgularının karşılaştırılması.

\begin{tabular}{|c|c|c|c|}
\hline & $\begin{array}{l}\text { Ameliyat } \\
\text { Öncesi }\end{array}$ & $\begin{array}{c}\text { Son } \\
\text { Muayene }\end{array}$ & p \\
\hline Göz içi basıncı (mmHg) & $39,22 \pm 9,47$ & $17,02 \pm 4,29$ & $<0,001^{\wedge}$ \\
\hline $\begin{array}{l}\text { Topikal antiglokomatöz } \\
\text { ilaç sayısı }(n)^{*}\end{array}$ & $3,47 \pm 0,92$ & $1,52 \pm 1,09$ & $<0,001^{\wedge}$ \\
\hline EIDGK $(\log M A R) * *$ & $1,50 \pm 0,61$ & $1,60 \pm 0,57$ & $0,046^{\wedge}$ \\
\hline $\begin{array}{l}\text { Merkezi kornea } \\
\text { kalınlığı }(\mu)\end{array}$ & $590,01 \pm 88,86$ & $655,25 \pm 170,88$ & $0,002^{\wedge}$ \\
\hline $\begin{array}{l}\text { Kornea ve grefon } \\
\text { yetmezliği }(n, \%)\end{array}$ & $8(16,6)$ & $12(\% 25)^{* * *}$ & $0,001^{\wedge \wedge}$ \\
\hline
\end{tabular}

*Kullanılan ilaçların etken maddesine göre numaralandırıldı, ** EIDGK: En iyi düzeltilmiş görme keskinliği, ***implant sonrası yeni gelişen kornea ödemi vaka sayısı ^Wilcoxon Signed Ranks Testi, ^^Ki-Kare Testi.

On iki vakada görme keskinliğinin azaldığı (en sık sebep kornea ödemi) bir vakanın ise ışık hissini kaybettiği (kontrolsüz glokom nedeniyle) görüldü. AGV implantasyonu sonrası yeni kornea ödemi meydana gelen 12 vakanın 5'i afakik glokom ve 5'i PK'ya sekonder glokom ve 2'si NVG vakasıydı. İmplantasyon öncesinde 4 PK vakasında hafif grefon ödemi, 1 vakada ise grefon yetmezliği mevcut iken, diğer alt gruplarda 3 kornea ödemi mevcuttu. Son muayene bulgularına bakıldığında 3 PK vakasında yeni grefon ödemi geliştiği, ancak yeniden keratoplasti gereksinimi oluşmadığı, ancak implantasyon öncesi grefonu saydam olan 2 vakada total grefon opaklaşması meydana geldiği ve bu vakalara ikinci PK uygulaması yapıldığı saptandı (Figür 1). Afakik glokom vakalarına bakıldığında son takiplerinde 5 vakada yeni kornea ödemi ve büllöz

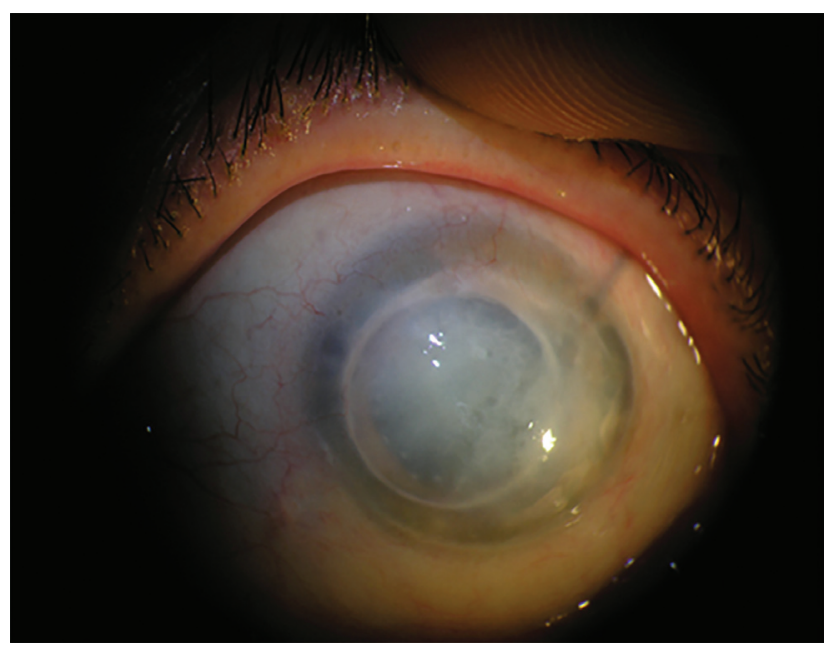

Figür 1. Ahmet valf implantasyonu öncesinde grefonu saydam olan bir vakanın operasyondan sonra 36 . aydaki görüntüsü. Grefonda total opaklaşma görülüyor.

keratopati geliştiği ve bu vakalardan birine PK uygulandığı saptandı. Büllöz keratopati gelişen afakik glokomlu 5 vakadan 2'sine tüp kısaltma cerrahisi uygulandığı görüldü.

Ameliyata bağlı gelişen bütün komplikasyonlar Tablo 3'te özetlendi. En sık karşılaşılan erken dönem komplikasyonu hipotoni (7 vaka), hipotoniye ikincil koroid efüzyonu ve dekolmanı (5 vaka) ve tüp ucunun tıkanmasıydı (7 vaka, en sık neden vitreus idi). Koroid efüzyonu ve dekolmanı cerrahi tedavi gerektirmeden GiB'ının normalleşmesiyle kendiliğinden düzeldi. Bir afakik glokom vakasında hipotoni makülopatisi gelişti. Ameliyat sonrası 10. günde bütün vakalarda GiB $\geq 5 \mathrm{mmHg}$ saptandı ve hipotoniye bağlı görme

Tablo 3. Ameliyat sırasında ve sonrasında gelişen komplikasyonlar.

\begin{tabular}{lll}
\hline & Sayı (\%) & Glokom tanı alt grubu (n) \\
\hline Suprakoroidal kanama & $1(2,1)$ & Afakik \\
Vitreus içi kanama & $1(2,1)$ & NVG \\
Koroid efüzyonu ve/veya koroid dekolmanı & $5(10,4)$ & PK (2), Afakik (2), Travmatik (1) \\
Hipotoni & $7(14,5)$ & Afakik (4), PK (2), Travmatik (1), \\
Hipotoni makülopatisi & $1(2,1)$ & Afakik \\
Retina dekolmanı & 0 & \\
Endoftalmi & 0 & NVG \\
Bakış kısıtıı̆ğı ve çift görme & $1(2,1)$ & Primer refrakter (1), Afakik (1), NVG(1) \\
Plak migrasyonu/tüpün yer değiştirmesi & $3(6,3)$ & Primer refrakter (2), Afakik (1) \\
Konjoktival erozyon & $3(6,3)$ & Afakik (5), NVG (2) \\
Tüp ucunun tikanması & $7(14,6)$ & NVG (3) Afakik (2), Primer dirençli (1) \\
Tüp-endotel teması & $6(12,5)$ & PK (2), Afakik (1) \\
Kornea/grefon opaklaşması & $3(6,3)$ & \\
\hline
\end{tabular}


Tablo 4. Valf implantasyonu sonrası geçirilen ilave cerrahiler.

\begin{tabular}{lll}
\hline İlave Cerrahi & \multicolumn{1}{c}{$\mathbf{n ( \% )}$} & Glokom tanı alt grubu \\
\hline Suprakoroidal hemoraji için drenaj, \% & $1(2,1)$ & Afakik (1) \\
Tüp ucu temizliği, \% & $5(10,4)$ & Afakik (5) \\
Tüp ucu kısaltılması, \% & $6(12,5)$ & NVG (3), Afakik (2), Primier dirençli (1) \\
Konjoktival erozyon düzeltmesi (plate veya tüp), \% & $3(6,3)$ & Primer refrakter (2), Afakik (1) \\
Plate ve/veya tüpün repozisyonu & $3(6,3)$ & Primer refrakter (2), Afakik (1) \\
Anteriyor/pars plana vitrektomi gereksinimi, \% & $5 / 2(10,4 / 4,2)$ & Afakik (5)/Afakik (2) \\
Yeni PK uygulaması (endotel yetmezliği için), \% & $3(6,3)$ & PK (2), Afakik (1) \\
AGV implantının çıkarılması, \% & $1(2,1)$ & Afakik (1) \\
Ilave siklodestriktif girişim, \% * & $5(10,4)$ & Afakik (3), NVG (2) \\
& & \\
\hline
\end{tabular}

NVG: Neovasküler glokom, PK: Penetran keratoplasti, AGV: Ahmed glokom valfi. *Uygulanan siklodestriktif girişimler; sikloekvatoryal kriyoterapi, diod lazer siklofotokoagülasyon ve endoskopik diod lazer siklofotokoagülasyon gibi işlemleri kapsamaktadır.

kaybı oluşmadı. Bir afakik glokom vakasında drenaj gerektiren suprakoroidal kanama meydana geldi ve bu vakaya aynı zamanda pars plana vitrektomi (PPV) uygulandı. Bir NVG vakasında vitreus içi hemoraji geliştiği için PPV uygulandı. Vakaların hiçbirinde retina dekolmanı ve endoftalmi gelişmedi. Altı vakada tüpendotel teması saptandı ve bu vakalara tüp ucu kısaltma cerrahisi uygulandı ( 3 vaka NVG, 2 vaka Afakik glokom ve 1 vaka primer dirençli glokom). Bir vakada plak migrasyonu, 2 vakada tüpün yer değiştirmesi ve 1 vakada bakış kısıtlılığı ve çift görme nedeniyle AGV repozisyonu yapıldı. Üç vakada tüpün konjonktivayı erode ettiği ve tüpün açığa çıktığı gözlendi. Bu vakalarda tutoplast, perikardiyum yama grefti ve amnion membran kullanılarak tüpün üzeri örtüldü.

En sık uygulanan ilave cerrahi tüp kısaltma cerrahisi ( $n=6, \% 12,5)$, ikinci sıklıkta tüp ucunun vitreusla tıkanması nedeniyle anteriyor vitrektomi uygulaması ve tüp ucu temizliği $(n=5, \% 10,4)$ ve $A G V^{\prime}$ nin yetersizliği nedeniyle siklodestrüktif cerrahi uygulaması olarak saptandı $(n=5, \% 10,4)$. İki saydam grefonlu PK vakasına grefon opaklaşması nedeniyle korneası saydam olan bir afakik vakaya korneal opaklaşma nedeniyle penetran keratoplasti uygulandı $(n=3, \% 6,3)$. Afakik glokom olan bir vakadan AGV çıkarıldı. Bu vakaya tüp ucunun vitreusla tıkanması nedeniyle $1 \mathrm{kez}$ anteriyor vitrektomi ve 2 kez tüp kısaltma cerrahisi uygulanmıştı. Bu vakada AGV'nin GiB'nı düşürmede yetersiz kalması (medikasyonla $36 \mathrm{mmHg}$ ) ve korneal ödemin ilerlemesi nedeniyle AGV çıkarıldı ve diod lazer siklofotokoagülasyon uygulandı. Valf implantasyonu sonrası geçirilen ilave cerrahiler Tablo 4'te belirtilirken, AGV tüp takılan farklı glokom tiplerindeki başarı oranları Tablo 5'te özetlenmiştir.

Tablo 5. AGV tüp takılan farklı glokom tiplerindeki başarı oranları.

\begin{tabular}{lllll}
\hline Glokom Tipi & $\begin{array}{c}\text { Tam } \\
\text { Başarı }\end{array}$ & $\begin{array}{c}\text { Kısmi } \\
\text { Başarı }\end{array}$ & $\begin{array}{c}\text { Total } \\
\text { Başarı }\end{array}$ & Başarısız \\
\hline Neovasküler $(n=13)$ & 7 & 4 & 11 & 2 \\
Afakik $(n=13)$ & 5 & 5 & 10 & 3 \\
PK'ye ikincil $(n=7)$ & 0 & 7 & 7 & 0 \\
Primer Refrakter $(n=6)$ & 5 & 1 & 6 & 0 \\
Konjenital $(n=4)$ & 3 & 1 & 4 & 0 \\
Travmatik $(n=5)$ & 2 & 3 & 5 & 0 \\
Toplam $(n=48)$ & $22(\% 46)$ & $21(\% 43,4)$ & $43(\% 89,4)$ & $5(\% 10,6)$ \\
\hline
\end{tabular}

\section{TARTIŞMA}

Ahmed glokom valvi, içerdiği valf mekanizması nedeniyle, dirençli glokom vakalarının cerrahi tedavisinde oldukça sık tercih edilen bir materyaldir ${ }^{6-10}$. Çünkü valf içermeyen diğer implantlarda erken dönemde hipotoni riski daha yüksektir ${ }^{5,6,11}$. Her ne kadar valfsiz tüpler üzerinde çeşitli modifikasyonlar yapılsa, tüpün sütürasyonla daraltılması gibi önlemler alınsa da valfli sistemlere göre erken hipotoni oluşma riski daha yüksektir ${ }^{12,13}$. Yapılan çalışmalar Ahmed valfin erken hipotoni riski bakımından güvenli olduğunu göstermişlerdir ${ }^{10,11}$. Çalışmamızda erken hipotoni oranı göreceli olarak yüksek saptandı ve özellikle afakik glokom vakalarında daha sık gözlendi. Ancak vakala- 
rın hiçbirinde görmeyi tehdit eden bir durum ortaya çıkmadan normal göz içi basıncı değerlerine ulaşıldı. Suprakoroidal hemoraji tek bir vakada, afakik glokom vakasında, erken postoperatif dönemde gelişti ve cerrahi drenaj uygulanmak durumunda kalındı. Literatürde de AGV implantasyonu sonrası suprakoroidal hemoraji gelişimi bildirilmiştir ${ }^{14,15}$.

Huang ve ark.'nın ${ }^{16}$ çalışmasında, tüp ucunun tıkanma oranı \%11 olarak belirtilmiş ve en sık komplikasyon olarak gözlenmiştir. Bizim çalışmamızda da en sık karşılaşılan komplikasyonlardan biri tüp ucunun tıkanmasıydı (\%14,6). Bu vakaların \%70'i afakik glokom vakasıydı ve en sık vitreusla, daha az sıklıkla da hemoraji ve fibrin membran ile tüp ucunun tıkandığı gözlendi. Yine çalışmamızda, diğer sık karşılaşılan komplikasyonlar tüpün veya valf gövdesinin konjonktivayı erode etmesi ve plate göçü idi $(\% 12,5)$. Cerrahi yöntem olarak vakaların hiçbirinde tüpün üzerini örtmek için ilave sklera veya perikard kullanılmaması konjonktival erozyon görülme oranının yüksek olmasına neden olmuş olabilir. Ameliyat prosedürümüzde tüpün konjonktival erozyon yapmaması için skleral tünel oluşturulup tüp bu tünelden geçirilerek ön kamaraya yerleştirildi. Ancak yine de konjonktival erozyon gözlendi. Nitekim Quaranta ve ark.'nın ${ }^{17}$ tüpün üzerini sığır perikardı ile örterek Ahmed valf implantasyonu yaptıkları bir çalışmada, 2 yıllık takiplerde hiçbir vakada konjonktival erozyon gelişmemiştir. Yine Wolf ve ark.'nın ${ }^{18}$ çalışmasında, serbest ve rotasyonel otolog skleral flep kullanarak Ahmed glokom valf implantasyonu yapılmış ve rotasyonel flebin konjonktival erozyonu önlemede daha etkin olduğunu saptanmıştır.

Çalışmada plak ve tüp göçü \%6,3 vakada görüldü. Literatürde bu tür vakalara özellikle konjenital glokom vakalarında rastlanmıştır ve gözün büyümesi ile ilişkilendirilmiştir ${ }^{19}$. Çalışmamızda, yalnızca bir vakada çift görme saptandı ve bu vaka üst nazale implantasyon yapılan ve plak migrasyonu saptanan bir diyabetik NVG vakasıydı. Repozisyon yapıldıktan sonra çift görme düzeldi. Özellikle Baerveldt ve Krupin gibi geniş plaklı implantlarda ve çocuklarda çift görme ve bakış kısıtıılığı gelişebildiği gösterilmiştir ${ }^{20,21}$. Yine Budenz ve ark.'nın ${ }^{22}$ çalışmasında, Ahmed ve Baerveldt valf- lerinin uzun dönem klinik sonuçları karşılaştırılmış ve her iki valf tipi için de kalıcı çift görme oranını yüksek saptamışlardır (\%12).

Literatürde tüp endotel teması sıklığı çeşitli çalışmalarda farklı oranlarda belirtilmiştir. Örneğin, Razeghinejad ve ark.'nın ${ }^{23}$ çalışmasında AGV takılan konjenital glokomlu vakalarda en sık komplikasyonun tüp-endotel teması olduğu bildirilmiştir. Çalışmada tüp endotel teması oranı \%17 saptandı. Çalışmamızda, tüp-endotel teması olan vakalara bakıldığında bunların \%50'sinin afakik glokom grubu olduğu görüldü. Tüp-endotel teması endotel yetmezliği ve kalıcı kornea ödemine yol açması nedeniyle önemli bir komplikasyondur ve bu durumu düzeltmek için tüpün kısaltılması, tüpün yerinin değiştirilmesi gibi literatürde bir çok yöntem tanımlanmıştı ${ }^{24,25}$.

Çalışmada saptanan geç dönem komplikasyonlara bakıldığında kalıcı kornea ödemi ve buna bağlı gelişen görme keskinliğindeki azalma oranının yüksek saptanması dikkatimizi çekti. Ameliyat öncesinde grefonu saydam olan iki penetran keratoplasti vakası ve korneası saydam olan bir afakik glokom vakası korneal endotel yetmezliği gelişmesi nedeniyle penetran keratoplasti cerrahisi geçirdi. Ameliyat öncesi kornea ödemi daha çok göz içi basıncı yüksekliğine bağlı epitel ödemi şeklindeydi. Ancak uzun dönem sonuçlara bakıldığında görme keskinliği azalan vakaların hemen hepsinde nedenin kornea veya grefonun opaklaşmasına bağlı geliştiği görüldü. Özellikle penetran keratoplastili ve afakik glokom vakalarında kornea yetmezlik oranı diğer dirençli glokom tiplerinden daha yüksek saptandı. Literatüre bakıldığında Budenz ve ark.'nın ${ }^{22}$ Baerveldt ve Ahmed valf implantlarının klinik karşılaştırmasını yaptıkları bir çalışmada, 5 yıllık sonuçları yayınlamışlar ve her iki grupta da korneal ödem oranının \%20 olduğunu belirtmişlerdir. Çalışmamızda bu oran \%25 olarak saptandı. Tüp-endotel teması olmayan gözlerde bile korneal yetmezliğin gelişebildiği görüldü. Bu vakalarda her ne kadar görünen bir tüp ucu-endotel teması olmasa bile hastanın gözünü kaşıması, fark etmeden gözüne bası uygulaması tüp-endotel temasına neden olabilir. Afakik veya psödofakik vakalarda tüp-kornea teması- 
nı engellemek için tüpün ucunun pars planadan irisin arkasına implante edilmesi de bir seçenektir ${ }^{26}$. Ancak bu vakalarda da erken dönemde sık görülen tüp ucu tıkanmasının görsel olarak değerlendirilmesi sorun oluşturabilir. Huang ve ark.'nın ${ }^{27}$ bir çalışmasında, penetran keratoplastili vakalara uygulanan endoskopik siklofotokoagülasyon (ECP) cerrahisinin hem göz içi basıncını etkin olarak düşürmede hem de postoperatif endotel hücre kaybının düşük olması bakımından oldukça avantajlı bulunmuştur. Çalışmamıza göre ameliyata bağlı gelişen komplikasyonlara bakıldığında; suprakoroidal kanama, hipotoni, tüp ucunun tıkanması ve kornea yetmezliği gibi komplikasyonların özellikle afakik glokom vakalarında daha yüksek oranda geliştiği saptanmıştır. AGV implantına bağlı gelişen uzun dönem korneal endotel hasarı önlemek için, korneası veya grefonu saydam olan afakik/psödofakik dirençli glokom vakalarına ECP cerrahisi uygulanabilir. Böylece AGV implantasyonu yapılan afakik glokom vakalarında daha sık saptadığımız tüp ucu tıkanması, tüp-endotel teması, erken hipotoni gibi komplikasyonların da önüne geçilmiş olur.

\section{Çalışmanın zayıf yönleri:}

Dönemin hastane fiziksel şartları nedeniyle eski hastalara speküler mikroskobik muayene yapılamadığı için endotel hücre sayımı yapılamadı ve Ahmed glokom valfinin endotel hücre sağlığı üzerindeki direkt etkilerini değerlendiremedik. Ancak, merkezi kornea kalınlığı ölçülerek vakaların kornea sağlığı dolaylı olarak da olsa değerlendirilebildi. Afakik glokom vakalarında gerek erken dönem gerekse geç dönem tüp komplikasyonlarının diğer alt grup dirençli glokom tiplerine göre daha yüksek oranda olduğu gözlendi. Ancak bu bilgilerin daha fazla afakik glokom vakasının yer aldığı çalışmalarla desteklenmesi gerekmektedir.

\section{SONUÇ}

Ahmed glokom valf implantasyonu dirençli glokom vakalarında erken dönem hipotoniye bağlı komplikasyon oranları düşük olan ve göz içi basıncını etkin bir şekilde düşüren bir cerrahi metottur. Ancak uzun dönemde, özellikle afakik ve penetran keratoplastili hastalarda, kornea ödemi ve endotel yetmezliği tablosu ortaya çıkabilmektedir. Bu nedenle korneası veya grefonu saydam olan dirençli afakik/psödofakik glokom vakalarında Ahmed valf implantasyonu yerine uzun dönemde kornea sağığını tehdit etmeyen endoskopik siklofotokoagülasyon gibi siklodestrüktif cerrahi uygulanması geç dönemde kornea yetmezliği tablosu ile karşılaşmamak için daha doğru bir yaklaşım olabilir.

\section{KAYNAKLAR}

1. Bayraktar Ş, Altan T, Özçelik F, Yılmaz ÖF. Tedaviye dirençli glokom vakalarında Ahmed Glokom Valvi uygulaması sonuçları. T Oft Gaz 2003;33:204-9.

2. Sanders SP, Cantor LB, Dobler AA, Hoop JS. Mitomycin C in higher risk trabeculectomy: a prospective comparison of 0.2to 0.4-mg/cc doses. J Glaucoma 1999;8:193-8. http://dx.doi.org/10.1097/00061198-199906000-00008

3. Ayyala RS, Pieroth $L$, Vinals $A F$, et al. Comparison of mitomycin-C trabeculectomy, glaucoma drainage device implantation, and laser neodymium:YAG cyclophotocoagulation in the management of intractable glaucoma after penetrating keratoplasty. Ophthalmology 1998;105:1550-6. http://dx.doi.org/10.1016/S0161-6420(98)98046-0

4. Wagle NS, Freedman SF, Buckley EG et al. Long term outcome of cyclocryotherapy for refractory pediaric glaucoma. Ophthalmology 1998;105:1921-6, discussion 1926-7.

5. Molteno AC. New implant for drainage in glaucoma. Animal trial. Br J Ophthalmol 1969;53:161-8.

http://dx.doi.org/10.1136/bjo.53.3.161

6. Allingham RR, Damji KF, Freedman $S$, et al. Glaucoma Drainage-Device Surgery. In: Shields Textbook of Glaucoma. 6th ed. Philadelphia, Lippincott Williams and Wilkins, 2011 pp:524-31.

7. Coleman AL, Hill R, Wilson MR, et al. Initial clinical experience with the Ahmed glaucoma valve implant. Am J Ophthalmol 1995;120:23-31. http://dx.doi.org/10.1016/S0002-9394(14)73755-9

8. Ozdal PC, Vianna RN, Deschenes J. Ahmed valve implantation in glaucoma secondary to chronic uveitis. Eye (Lond) 2006;20:178-83.

http://dx.doi.org/10.1038/sj.eye.6701841

9. Li Z, Zhou M, Wang W, et al. A prospective comparative study on neovascular glaucoma and non neovascular refractory glaucoma following Ahmed glaucoma valve implantation. Chin Med J 2014;127:1417-22.

10. Lai JS, Poon AS, Chua JK, et al. Efficacy and safety of the Ahmed glaucoma valve implant in Chinese eyes with complicated glaucoma. Br J Ophthalmol 2000;84:718-21. http://dx.doi.org/10.1136/bjo.84.7.718

11. Nassiri N, Kamali G, Rahnavardi M et al. Ahmed glaucoma valve and single-plate Molteno implants in treatment of refractory glaucoma: a comparative study. Am J Ophthalmol 2010;149:893-902. http://dx.doi.org/10.1016/j.ajo.2010.01.025

12. Heuer DK, Lloyd MA, Abrams DA et al. Which is better? One or two? A randomized clinical trial of single-plate versus double-plate Molteno implantation for glaucomas in aphakia and pseudophakia. Ophthalmology 1992;99:1512-9. 
http://dx.doi.org/10.1016/S0161-6420(92)31772-5

13. Gerber SL, Cantor LB, Sponsel WE. A comparison of postoperative complications from pressure-ridge Molteno implants versus Molteno implants with suture ligation. Ophthalmic Surg Lasers 1997;28:905-10.

14. Huang J, Lin J, Wu Z, et al. Outcomes of Ahmed glaucoma valve implantation in advanced primary congenital glaucoma with previous surgical failure. Clin Ophthalmol 2015;9:977-83. http://dx.doi.org/10.2147/OPTH.S83820

15. Lavinsky F, Moisseiev J, Levkovitch-Verbin H. The surgical management of massive intraoperative and postoperative suprachoroidal hemorrhage: anatomic and functional outcomes. Arq Bras Oftalmol 2013;76:212-4. http://dx.doi.org/10.1590/S0004-27492013000400003

16. Huang MC, Netland PA, Coleman AL, et al. Intermediate-term clinical experience with the Ahmed Glaucoma Valve implant. Am J Ophthalmol 1999;127:27-33. http://dx.doi.org/10.1016/S0002-9394(98)00394-8

17. Quaranta L, Riva I, Floriani IC. Outcomes of using a sutureless bovine pericardial patch graft for Ahmed glaucoma valve implantation. Eur J Ophthalmol 2013;23:738-42. http://dx.doi.org/10.5301/ejo.5000260

18. Wolf A, Hod Y, Buckman G, et al. Use of Autologous Scleral Graft in Ahmed Glaucoma Valve Surgery. J Glaucoma 2015. [Epubahead of print] http://dx.doi.org/10.1097/IJG.0000000000000232

19. Netland PA, Walton DS. Glaucoma drainage implants in pediatric patients. Ophthalmic Surg 1993;24:723-9.
20. Cardakli UF, Perkins TW. Recalcitrant diplopia after implantation of a Krupin valve with disc. Ophthalmic Surg 1994;25:256-8.

21. Mu-Oz M, Parrish RK 2nd. Strabismus following implantation of Baerveldt drainage devices. Arch Ophthalmol 1993;111:1096-9. http://dx.doi.org/10.1001/archopht.1993.01090080092023

22. Budenz DL, Feuer WJ, Barton K, et al. Postoperative Complications in the Ahmed Baerveldt Comparison study During Five Years of Follow-up. Am J Ophthalmol 2015; pii: S00029394(15)00711-4

23. Razeghinejad MR, Kaffashan S, Nowroozzadeh MH. Results of Ahmed glaucoma valve implantation in primary congenital glaucoma. J AAPOS 2014;18: 590-5. http://dx.doi.org/10.1016/j.jaapos.2014.08.008

24. Ma KT, Kim JH, Seong GJ et al. Scleral fixation of Ahmed glaucoma valve tube tip for adjustment of cornea-touching malposition. Eye (Lond) 2014;28:23-5. http://dx.doi.org/10.1038/eye.2013.214

25. Dada T, Gupta R, Tinwala SI et al. Repositioning of Ahmed glaucoma valve tube in the anterior chamber with prolene sutures to manage tube-endothelial touch. Nepal J Ophthalmol 2012;4:309-11. http://dx.doi.org/10.3126/nepjoph.v4i2.6549

26. Chihara E, Umemoto M, Tanito M. Preservation of corneal endothelium after pars plana tube insertion of the Ahmed glaucoma valve. Jpn J Ophthalmol 2012;56:119-27. http://dx.doi.org/10.1007/s10384-011-0108-1

27. Huang T, Wang YJ, Chen JQ, et al. Effect of endocyclophotocoagulation on survival of corneal grafts. Zhonghua Yan Ke Za Zhi 2007;43:313-8. 